\title{
Using laboratory and in situ data to develop a tailings cover design model
}

\author{
P.J. Chapman Golder Associates Pty Ltd, Australia \\ D.J. Williams School of Civil Engineering, The University of Queensland, Australia
}

\begin{abstract}
Developing models that mimic real world conditions is challenging. In many cases, data to suitably quantify the behaviour of the materials in question are unavailable to the designer, and assumptions must be made. This can lead to an overly conservative model, which in turn results in conservative and most likely more expensive solutions. This is of particular of relevance to the closure of tailings storage facilities, where costs can increase significantly from estimates made during project initiation and operations.

In arid Western Australia, in situ moisture content and matric suction measurements of the desiccation and re-saturation cycles of sulphide nickel tailings have been collected over a period of about two years. A laboratory column experiment has also been carried out to mimic the deposition and drying cycles and provide additional data, under controlled conditions, to estimate the ponding depth required to infiltrate through the full depth of desiccated tailings. These data were used as a basis to develop a preliminary cover design model, in which the desiccated tailings are incorporated into a store and release cover system, minimising the need for additional cover materials and resulting in a significant economic saving to the mine. The key outcomes of the preliminary model are presented, along with a general description of the parameters required to develop similar models.
\end{abstract}

\section{Introduction}

During the operational period of a tailings storage facility (TSF), significant quantities of water are typically used to transport the tailings solids in a slurry form. The resulting volume of water that is placed with the tailings over the TSF footprint is significantly more than incident rainfall by about an order of magnitude, and a proportion of this water, typically around $10 \%$ to $15 \%$ in the authors' experience, will seep through the base of the TSF, resulting in a hydraulic connection with the groundwater and localised groundwater mounding beneath the supernatant pond. Figure 1 (developed by Professor David J. Williams in 2009) shows this process schematically.

As tailings operations continue, active measures such as seepage water recovery via production bores are sometimes required to maintain the groundwater level below the agreed compliance limit, typically described in terms of a depth below natural ground level. Seepage recovery can often continue throughout operations and well into closure.

During operations, the tailings typically cycle between saturation and unsaturated states as part of deposition cycles. After the cessation of operations, however, infiltration of slurry water no longer occurs, reducing the recharge to the system and hence the phreatic level within the tailings begins to fall, more rapidly near the perimeter embankments where there is coarser material of relatively higher hydraulic conductivity, and more slowly near the centre of the TSF (at the decant pond) where the material is finer and hence has a lower hydraulic conductivity.

Over time, the tailings may drain down completely. However, this is dependent on the climatic setting of the TSF (discussed in more detail in Section 3). The rate of decrease in the phreatic surface elevation is related to the rate at which incident rainfall 'tops up' the drained pore spaces within the tailings. In a tropical environment, where rainfall exceeds evaporation, the tailings may remain saturated due to the net 
water gain and seepage would continue. In an arid environment, such as the climatic setting for the site in question, evaporation is much greater than rainfall and there is a net water loss from the tailings, resulting in a reduction of the phreatic surface. This is shown schematically in Figure 2 (modified from Figure 1).

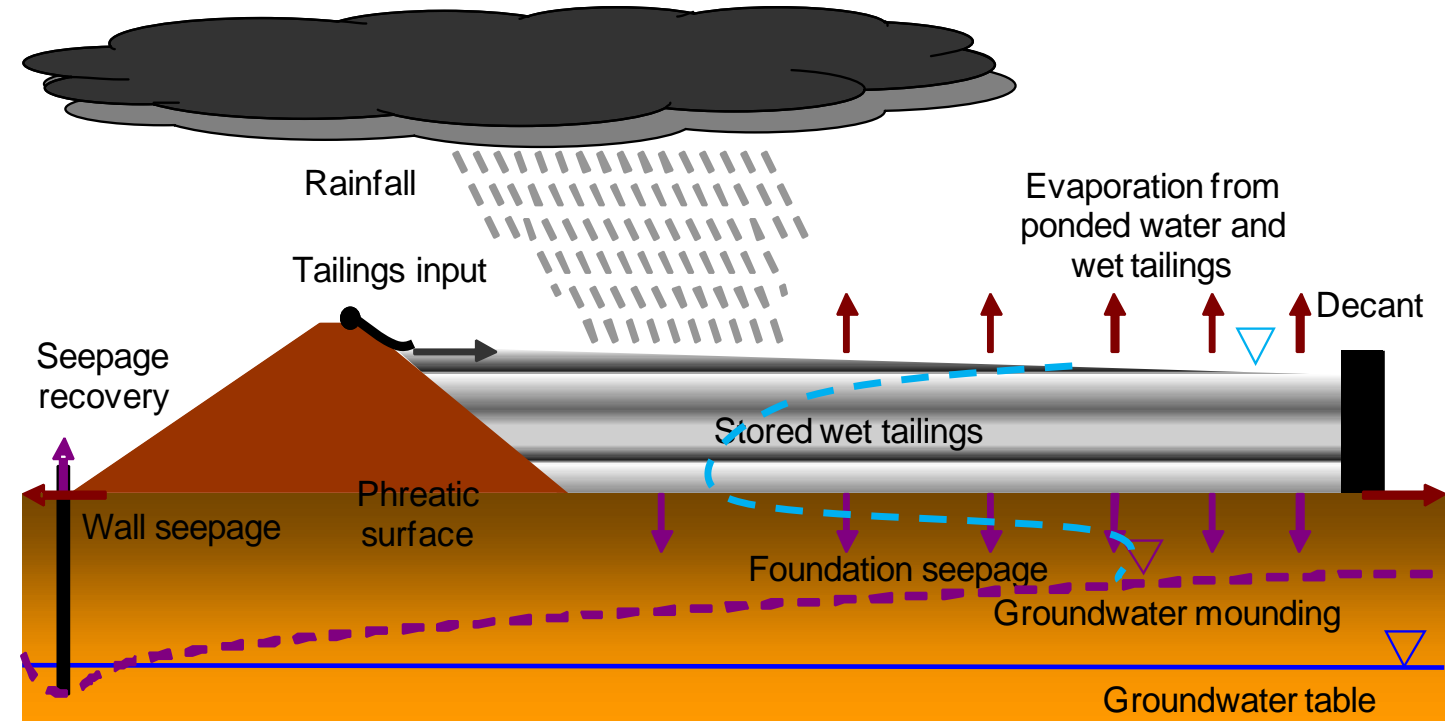

Figure 1 Typical impact of tailings deposition on groundwater

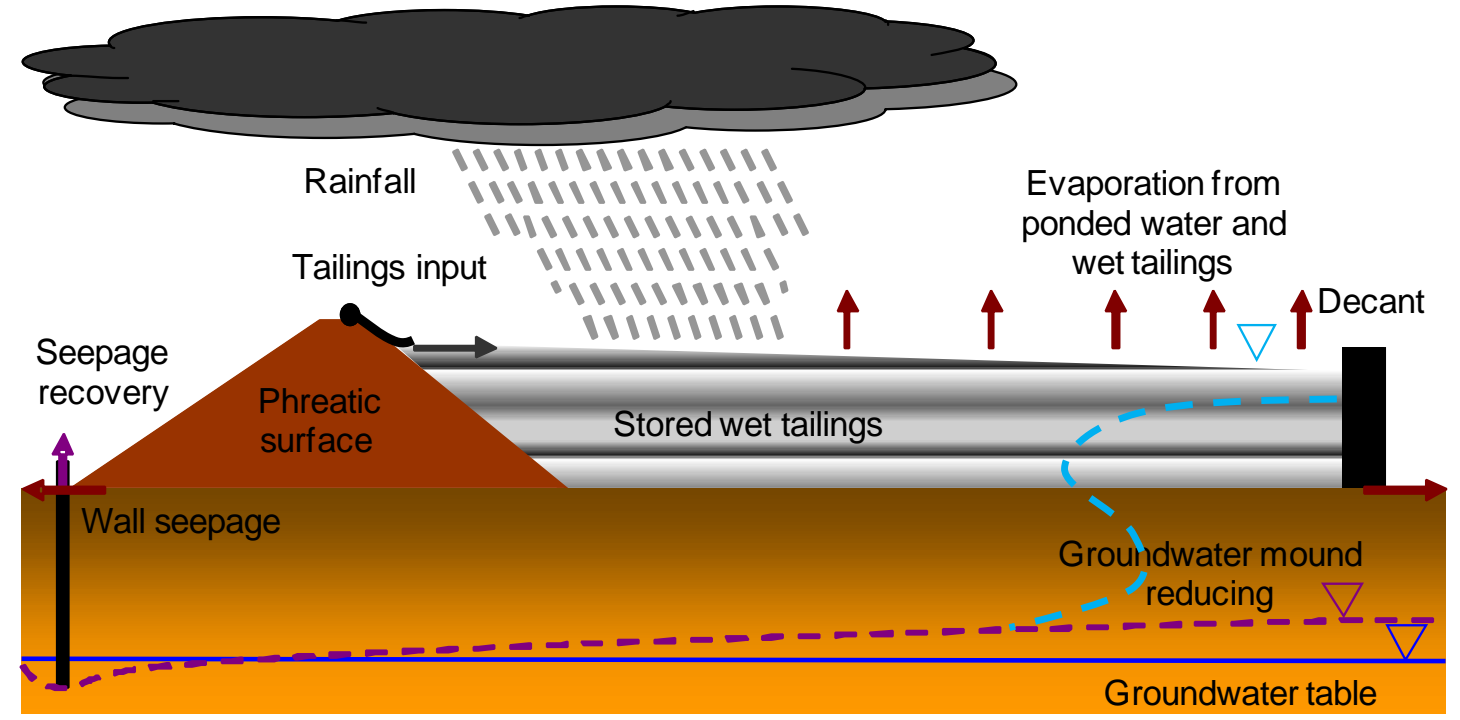

Figure 2 Long-term drain down of tailings in an arid environment

The extent to which the tailings re-wet during rainfall events and whether the tailings beneath the supernatant pond allow the rainfall to infiltrate to the point of recreating the hydraulic connection with the groundwater has not been researched in detail. The aim of the current project, which is still in progress, is to identify whether or not the tailings will desiccate to the point that incident rainfall, even if at times heavy, will infiltrate and recharge the full depth of tailings and hence re-form a hydraulic connection with the groundwater, causing seepage to the environment.

One of the key aspects of the project is the development of a numerical model to test the above hypothesis. This paper presents a brief summary of monitoring data collected at a site in arid Western Australia and the testing and monitoring of a laboratory tailings column under controlled conditions at The University of Queensland (UQ). The laboratory data were used to calibrate a preliminary numerical model, which was then used to predict the extent of infiltration of ponded rainfall through a one-dimensional 
tailings column, with a depth equivalent to that in the field. The key outcomes of the preliminary model are presented, along with a general description of the parameters required to develop similar models.

\section{$2 \quad$ Previous work}

Chapman et al. (2008) presented the preliminary results from the research project being carried out by the senior author under the supervision of Professor David J. Williams of UQ, and with support from Xstrata Nickel Australasia (Xstrata), the current owners of Cosmos Nickel Project (Cosmos). Chapman et al. (2008) focused on providing an overview of the challenges identified in relation to closure of the Cosmos TSF and presented preliminary outcomes of instrumentation installed within a trial TSF cell. The paper presented monitoring data collected to 31 December 2007. These data suggested that:

- Rapid desiccation occurs following the cessation of tailings deposition, including desiccation of the foundation.

- Rapid wetting-up of the desiccated tailings occurs during deposition of fresh tailings or rainfall.

- The majority of the considerable surplus water evaporates.

Chapman et al. (2008) concluded that it is possible that, if the tailings are allowed to desiccate for a sufficiently long time period, rainfall events after closure will not recharge the tailings sufficiently to reform a hydraulic connection with the groundwater, thus resulting in negligible long-term seepage. The purpose of any cover would then be to limit dust generation, and promote some vegetation through storage of water, rather than to shed rainfall runoff, which would result in a poor vegetative cover and erosion.

Chapman et al. (2009) expanded on the data presented in Chapman et al. (2008), with a focus on the unsaturated behaviour of the tailings and the impact of rainfall events, taking cognisance that rainfall and slurry deposition water collected at the pond, limiting infiltration into the beach. The matric suction data presented in Chapman et al. (2009) indicated that while most of the desiccation occurs towards the surface of the tailings, some desiccation occurs throughout the full depth of the tailings and even into the foundation (Sensor 1, at a depth of approx. $4 \mathrm{~m}$ ). This is shown in Figure 3, reproduced from Chapman et al. (2009). The periods in which there is an increase in matric suction represent desiccation through evaporation, while matric suctions decrease towards zero on tailings deposition. Once tailings deposition re-commences, the matric suctions indicate that the tailings and the foundation re-saturate, suggesting that a hydraulic connection through the tailings is re-established despite a significant amount of the slurry water running off.

Based on these data, Chapman et al. (2009) concluded that, during operations, the saturated and unsaturated states of the tailings can be directly linked to tailings deposition and desiccation (dormant) cycles: an unsaturated state is maintained within the dormant tailings beaches during rainfall events.

The work presented in this paper extends on the work previously published, with a focus on the preliminary numerical model developed to mimic infiltration into the tailings due to ponding of rainfall.

\section{$3 \quad$ Climatic setting and cover options}

\subsection{Climatic setting of Cosmos nickel project}

\subsubsection{Rainfall}

A summary of the site rainfall over a two-year period, including both the weather station (located on the TSF) and Cosmos site recordings, is shown in Figure 4. 
Suction Data Collected from Northern Tower Deposition over 18 Months

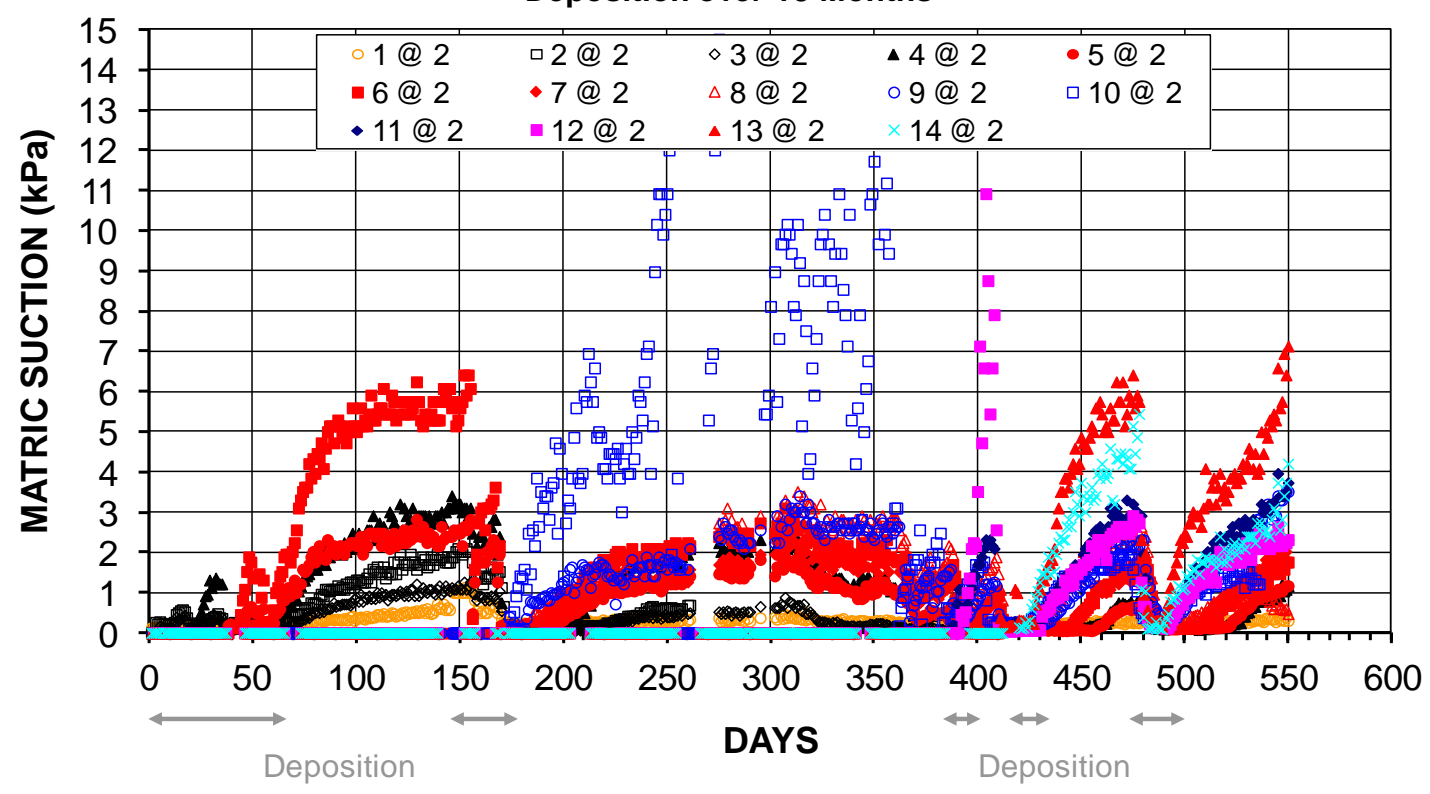

Figure 3 Matric suction versus time (after Chapman et al., 2009)

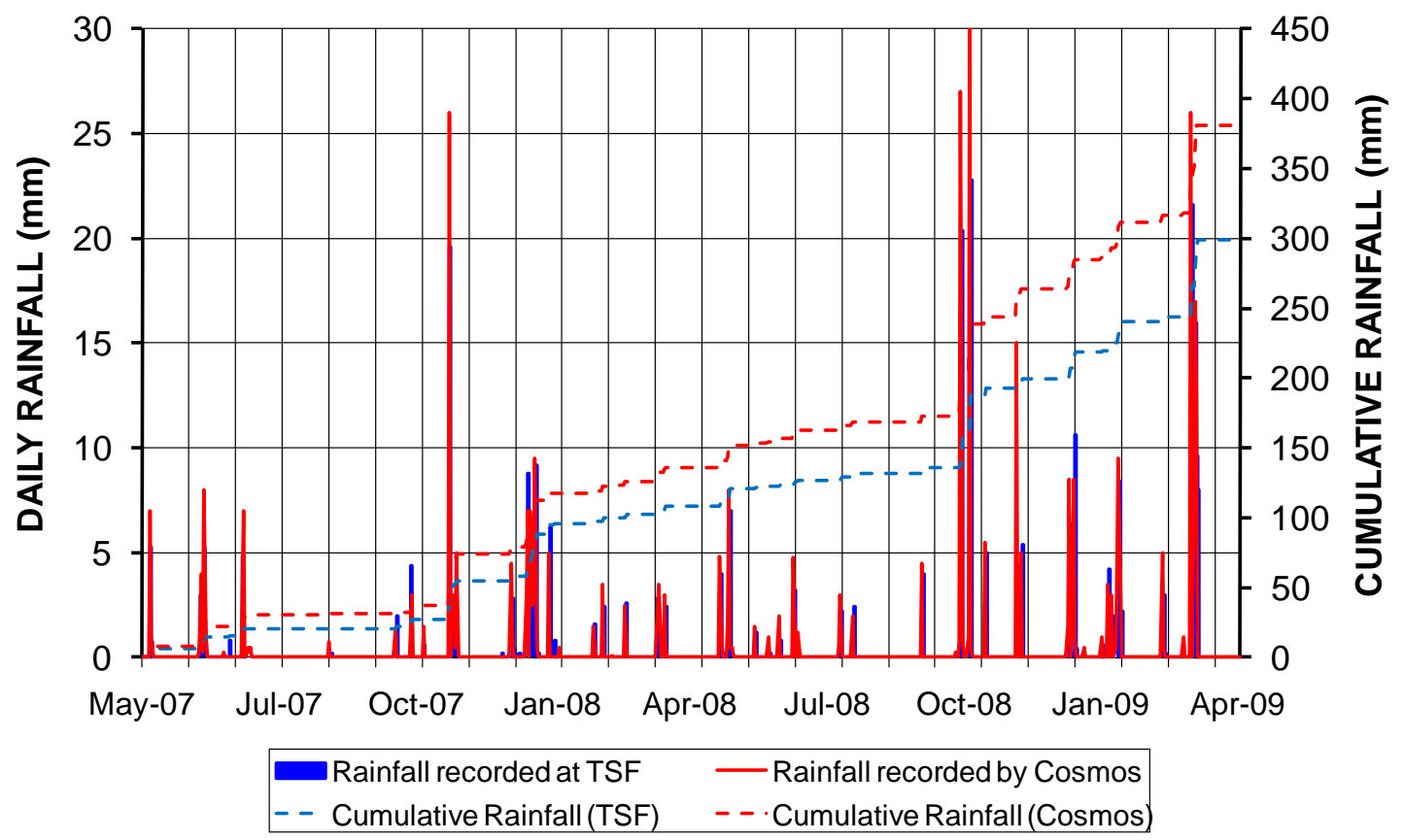

Figure 4 Rainfall data collected at Cosmos site and TSF

The rainfall comparison shown in Figure 4 indicates that the rainfall recorded by Cosmos site is consistently higher than that recorded at the TSF; the latter averaging $150 \mathrm{~mm}$ on an annual basis over the period, with $53 \mathrm{~mm}$ falling in summer and $17 \mathrm{~mm}$ in winter. The average annual rainfall for the site is $238 \mathrm{~mm}$, based on data collected at the nearest weather station (Yeelirrie, Western Australian weather station) over an extended period of time (BoM, 2012).

\subsubsection{Potential evaporation}

Potential evaporation was estimated using data collected on site and the method outlined in Allen et al. (1998). The FAO Penman Monteith method, which is a modification of the Penman Monteith method made by the Food and Agriculture Organization (FAO) of the United Nations (Allen et al., 1998), estimates daily 
potential evaporation values from the climate data (air temperature, relative humidity, wind speed, and net solar radiation) recorded at the weather station.

The predicted potential evaporation for the Cosmos TSF is shown in Figure 5. The average evaporation rate is estimated to be about $4.4 \mathrm{~mm} /$ day, equivalent to $1,605.5 \mathrm{~mm}$ annually, although there is clearly a seasonal trend, with a higher average rate of $6.4 \mathrm{~mm} /$ day during the hotter, summer months, decreasing to an average rate of $1.9 \mathrm{~mm} /$ day during the cooler, winter months.

The estimated annual evaporation rate of $1,605.5 \mathrm{~mm}$ is about seven times higher than the average annual rainfall $(240 \mathrm{~mm})$.

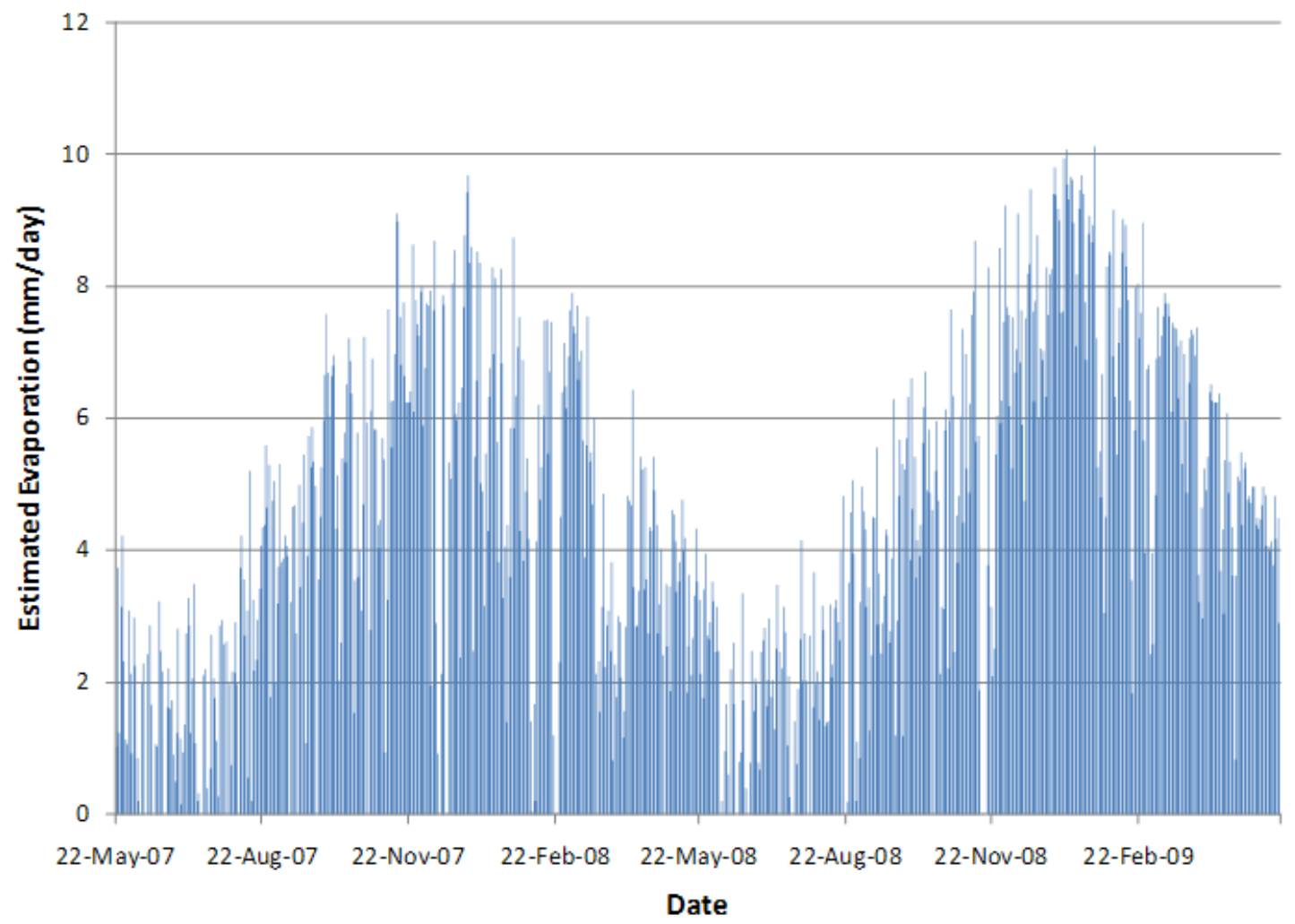

Figure 5 Estimated potential evaporation for the Cosmos TSF

\subsubsection{Climate classification}

Based on the aridity index defined by UNEP (1992), Cosmos has an arid climate, by virtue of a ratio between rainfall and potential evaporation of 0.15 .

\subsection{Cover options}

Various types of cover systems have been considered in the landfill industry for many years, many of which are also applicable to the closure of TSFs. Qian et al. (2002) states that the main purpose of a landfill final cover is to minimise water infiltration into the landfill to reduce the amount of leachate generated after closure. This purpose is typically the same for TSFs, except that the aim is commonly to reduce infiltration to minimise long-term seepage to the surrounding groundwater. The recently published draft guideline on TSF design, ANCOLD (2011), suggests that "closure options need to be reviewed on a case by case basis as there are likely to be specific issues to be addressed in each case". This statement is considered to be the crux of closure design, as one solution is not suitable for all sites. This is clearly shown by the range of cover types presented in Qian et al. (2002) and the climates in which they are generally implemented. Figure 6, published by The International Network on Acid Prevention (INAP, 2009) presents the typical cover types available to a designer, with respect to climate classification. 


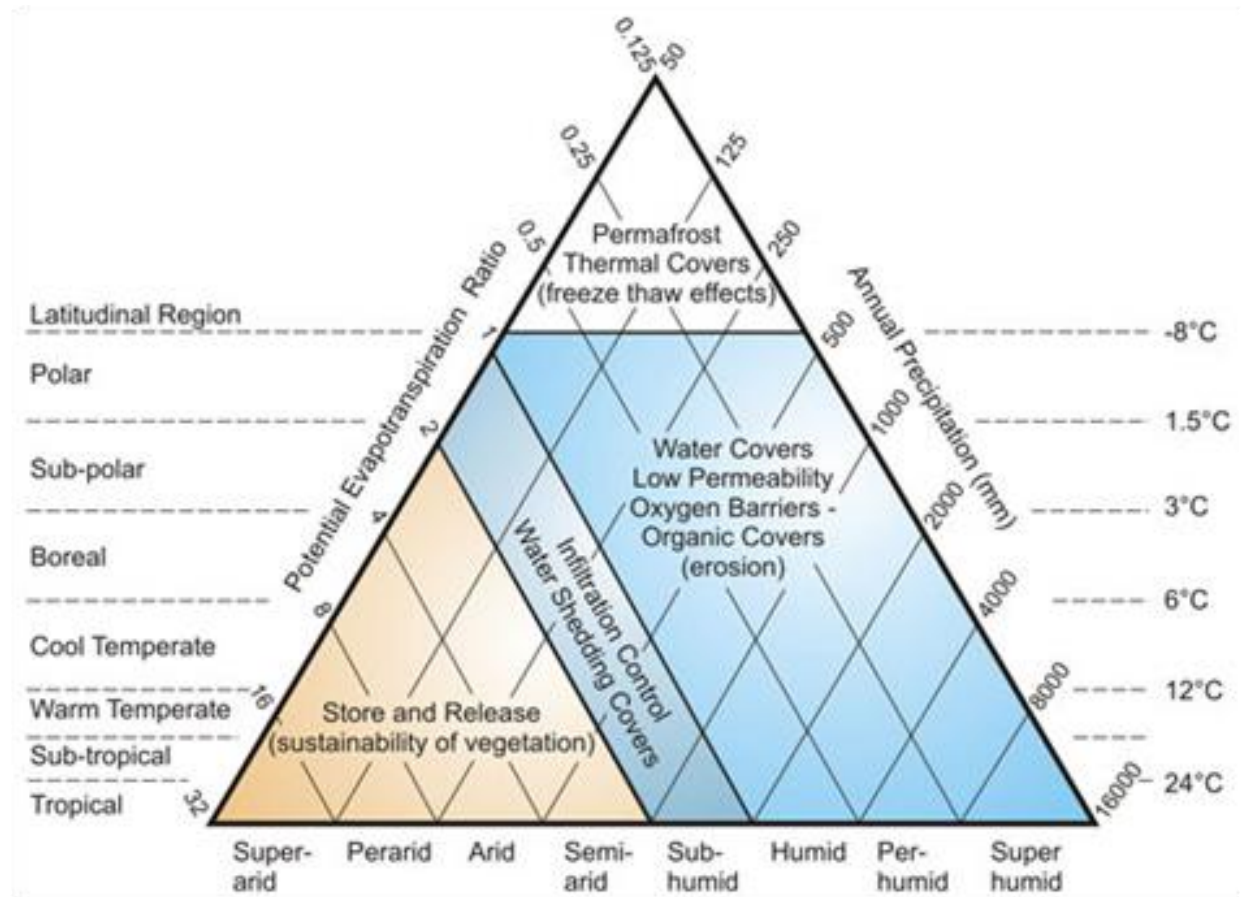

Figure 6 Covers and climate types, modified by Wickland and Wilson (INAP, 2009)

In the case of Cosmos, which has an arid climate as outlined in Section 3.1.3, a store and release cover over the upper surface of the TSF is likely to be most suitable. It is likely that a water-shedding cover, in place on the slopes, could also be made to work on the surface provided that it was designed and implemented properly, but ongoing maintenance may be required, especially after heavy storms often conducive to erosion. A net infiltration cover is not considered to be acceptable at this site due to environmental and groundwater issues, however, a discussion of this aspect of the closure design is beyond the scope of this work.

A store and release cover allows for incident rainfall to be collected in the cover system (stored) and evaporated (released), with minimal net percolation through the basal layer of the cover. In the arid interior of Western Australia, as at the Cosmos site, the rainfall distribution is such that wet spells are typically separated by extended dry spells (e.g. weeks-to-months) which promotes rapid drying to residual moistures and suctions well before the next major wet spell arrives. To further reduce costs, while still retaining the basic intent and function of the cover proper, the upper layers of tailings could be incorporated into the store and release cover, effectively using the low hydraulic conductivity of the desiccated tailings as the 'sealing' layer at the base of the cover.

\section{$4 \quad$ Model parameters and calibration}

\subsection{Column experiment}

Field data have been collected over a two-year period at the Cosmos trial TSF cell. The field data suggest that rapid desiccation occurs following the cessation of tailings deposition, throughout the tailings depth, which results in the tailings becoming unsaturated (Chapman et al., 2008). However, developing a model to represent the field conditions is challenging due to the large number of variables that exist. Among these variables are particle segregation down the beach, variable climatic conditions, and ongoing cyclical deposition and consolidation of the tailings over time. To minimise the number of variables that would need to be considered in order to calibrate a model, a laboratory column experiment was carried out at UQ to reflect conditions likely to be encountered at the supernatant pond of the TSF. 
Details regarding the column experiment are beyond the scope of this paper and will be published separately. However, for the purposes of modelling, the following aspects of the column experiment are pertinent:

- A $2 \mathrm{~m}$ high by $300 \mathrm{~mm}$ diameter column was instrumented with CSL229 water potential sensors (Campbell Scientific Inc., 2009) at $200 \mathrm{~mm}$ height intervals.

- Layers of tailings provided by Cosmos were placed into a column, at the solids consistent with deposition on site, in approximately $220 \mathrm{~mm}$ thick layers.

- After settling, excess water was removed from the surface, leaving a thin (approx. $50 \mathrm{~mm}$ ) layer.

- Measurements of the settlement of each layer were taken to allow dry density to be estimated.

- A lamp was placed near the surface of the tailings and each layer was allowed to desiccate, prior to placement of the subsequent layer.

- A CS215 temperature and relative humidity probe (Campbell Scientific Inc., 2010) was placed near the surface of the tailings during desiccation periods (see Figure 7).

- After allowing the final layer to desiccate for a period of time, ponds equivalent to a $100 \mathrm{~mm}$ and a $50 \mathrm{~mm}$ rainfall event were simulated on the surface of the tailings and allowed to infiltrate into the tailings. The lamp was replaced near the water surface to simulate subsequent evaporation (see Figure 8). Consistent with field conditions, cracks had developed (see Figure 7) and infiltration through these cracks occurred. However, the macro-scale infiltration was measured via the instrumentation.

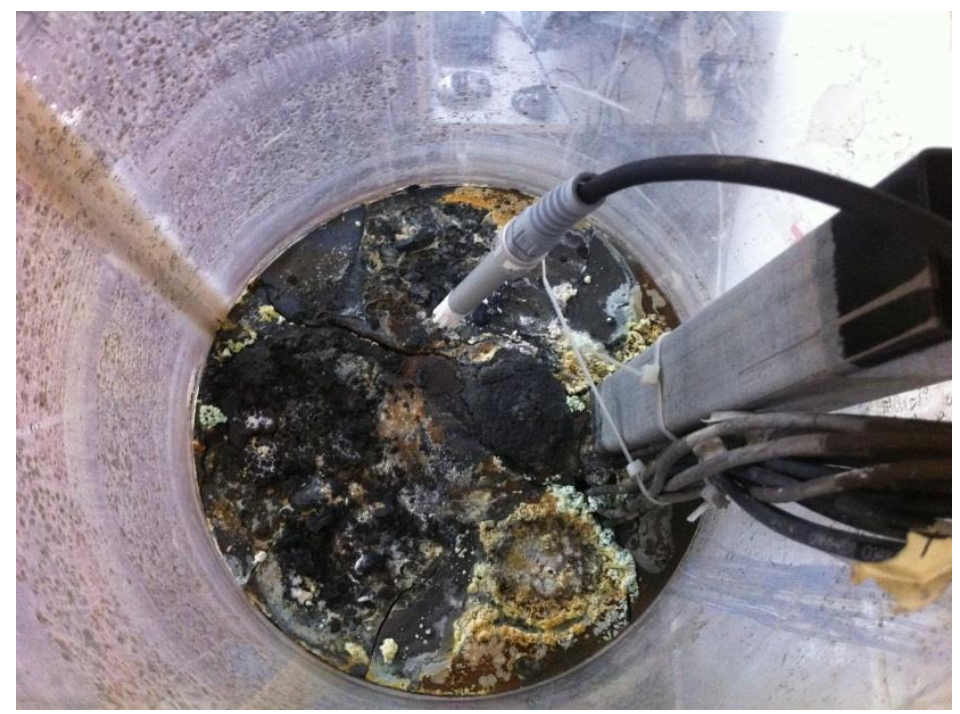

\section{Figure 7 Final layer of tailings with temperature / relative humidity probe}

\subsection{Model parameters}

The temperature and relative humidity data shown in Figure 9 was collected during the desiccation of the final tailings layer. The variations between days 2 and 3 indicate the time at which water was allowed to pond on the surface of the tailings. These data were used to calibrate a numerical model. The commercially available software package SVFlux, developed by SoilVision Systems Ltd, was used to model the tailings column. The model allows a climate boundary condition to be included, with parameters controlled in the column experiment (temperature and relative humidity) included and other parameters, such as wind and solar radiation, set to zero. 


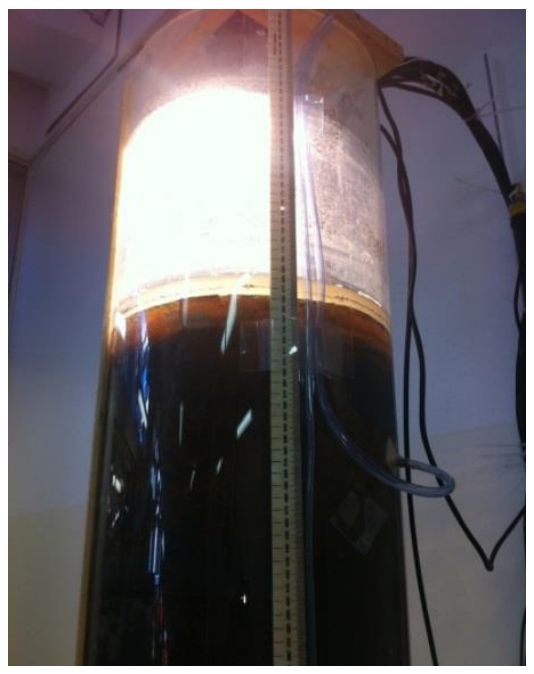

Figure 8 Tailings column after simulated ponding event

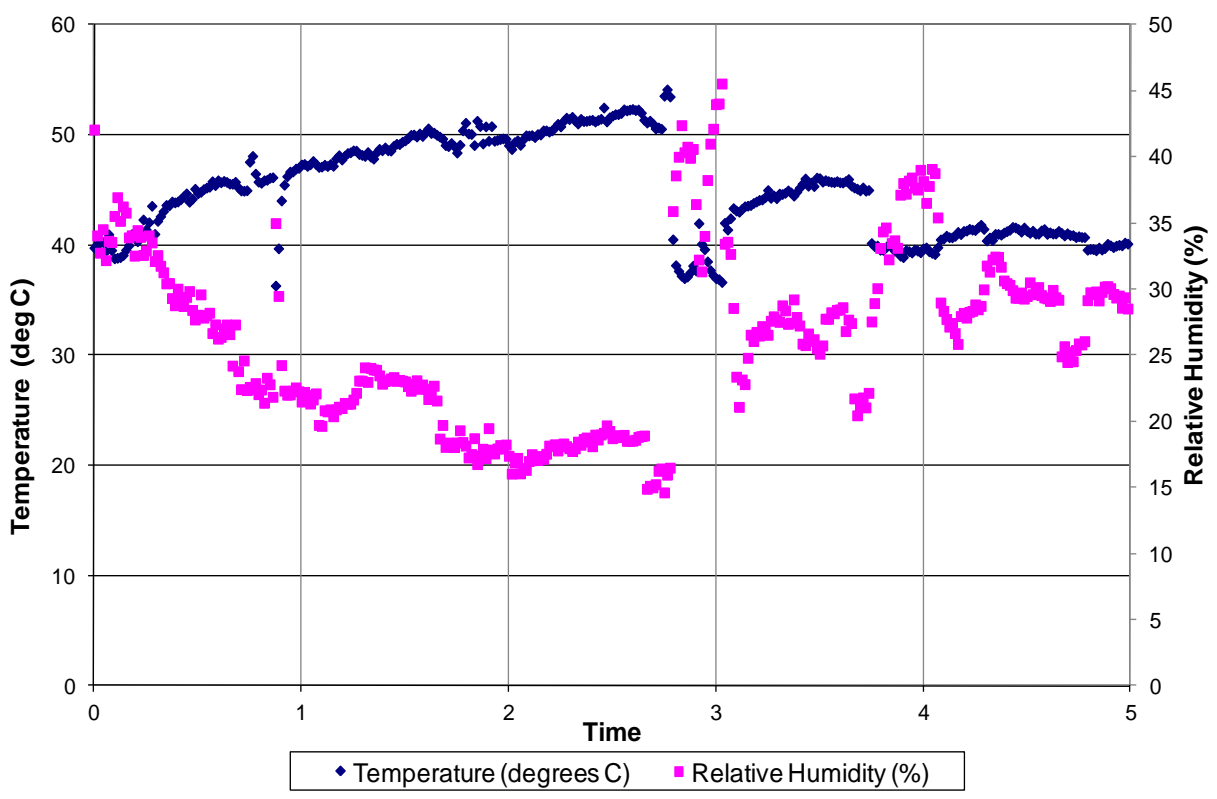

Figure 9 Temperature and relative humidity data collected

In addition to the climatic conditions, material-specific parameters are required to develop the model. These parameters include the tailings porosity, saturated hydraulic conductivity, and soil water characteristic curve. From this information, the unsaturated hydraulic conductivity function was estimated using the method of Fredlund et al. (1994). The porosity was calculated using measurements of the thickness of each tailings layer and the saturated hydraulic conductivity was measured in previous laboratory testing carried out by Golder Associates. The soil water characteristic curve, the key parameter in the authors' opinion, was measured in the laboratory using a SWC-150 Fredlund SWCC Device and estimated from the particle size distribution using the Fredlund et al. (1997). The measured and estimated curves are presented in Figure 10, with Prospero indicating the tailings type used in the test.

A discussion of the confidence in the estimation techniques in comparison with water retention data collected in the laboratory is beyond the scope of this paper. However, it is noted that the estimated soil water characteristic curve and the measured characteristic curve are similar above a saturation ratio of 0.7 . 


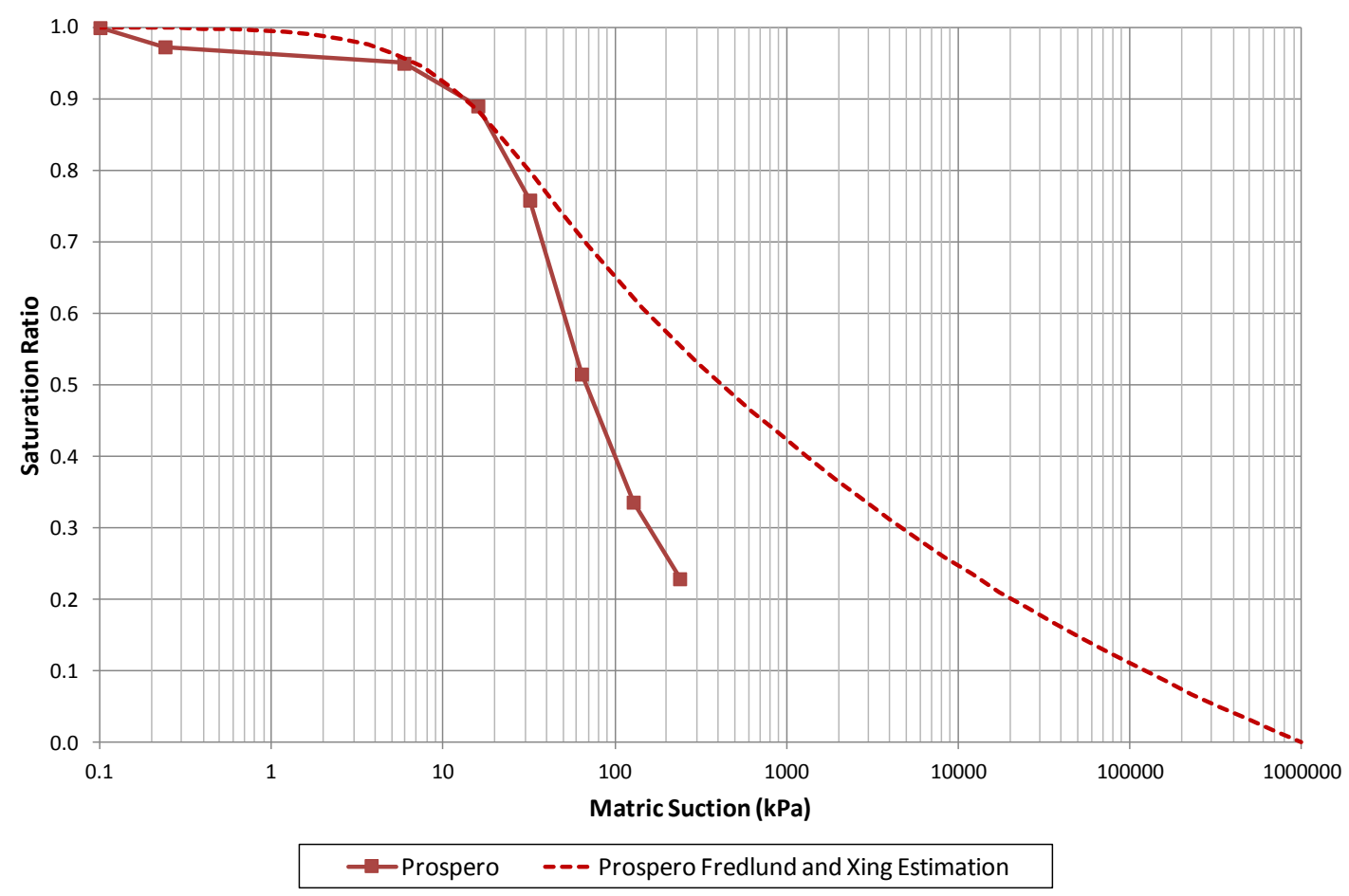

Figure 10 Measured and estimated soil water characteristic curve data

\subsection{Model calibration}

For the preliminary modelling, the measured soil water characteristic curve was initially adopted, along with the porosity measured from the laboratory column and the laboratory-measured saturated hydraulic conductivity. An initial model was developed with no changes to the soil water characteristic curve or other parameters. The outcomes of the model are graphed against measured matric suction data collected from three locations within the column in Figure 11. The three locations are spread across the full length of the tailings, with Layer 1 near the base, Layer 7 near the surface, and Layer 4 at mid-height.

Figure 11 indicates that the model results do not correlate well with the matric suction data collected from near the base of the column experiment (Layer 1). However, there is a reasonable correlation for the middle and upper layers. To check the sensitivity of the model, the air entry value of the soil water characteristic curve was increased and the model run repeated. The results of the model with the modified soil water characteristic curve are shown in Figure 12.

The results in Figure 12 indicate that the model reasonably captured the change in matric suction in the base layer, however, the upper and middle layers are not as well represented. Given the focus on the surface of the tailings and the purpose of identifying whether rainfall is likely to infiltrate (indicated by a decrease in matric suction at depth) the calibration based on the measured soil water characteristic curve (Figure 11) was considered to be acceptable for the preliminary modelling. It is acknowledged that the matric suction predicted at depth may be slightly higher than would be expected in the field and hence further calibrations will be carried out as modelling progresses. 


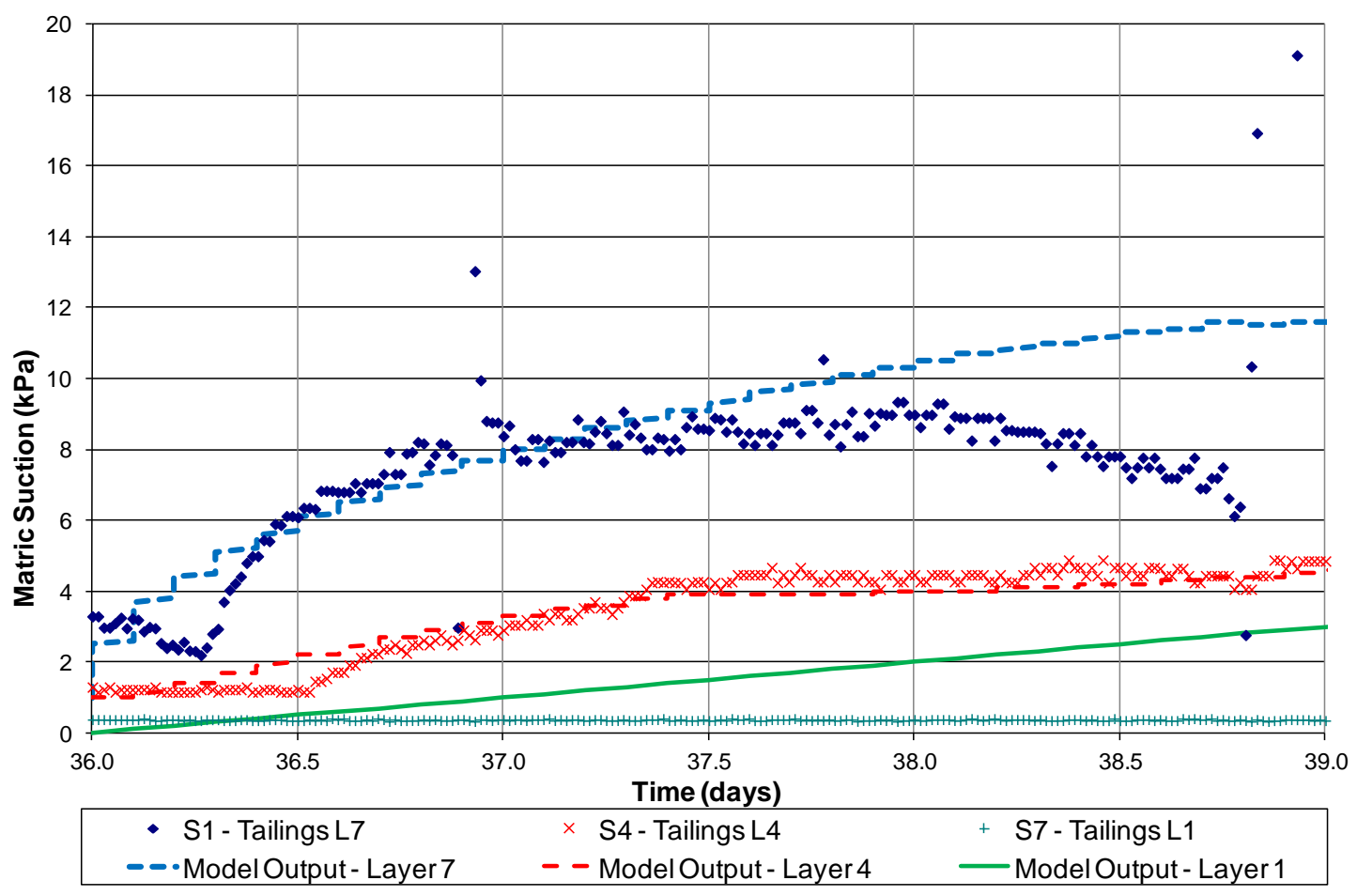

Figure 11 Model outcomes using measured soil water characteristic curve data

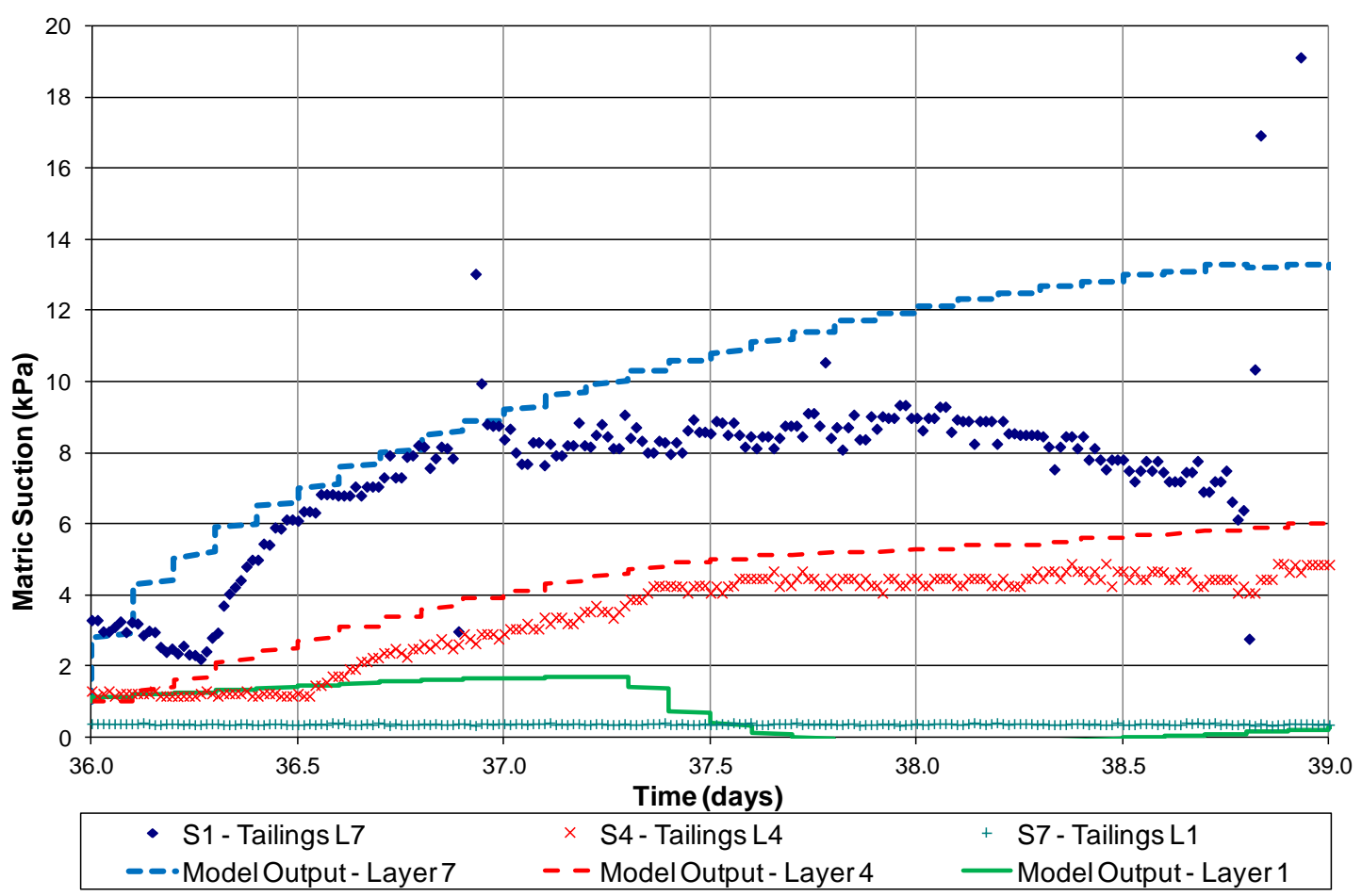

Figure 12 Model outcomes using modified soil water characteristic curve data

\section{$5 \quad$ Numerical modelling}

\subsection{Purpose and parameters}

The purpose of the preliminary numerical modelling was to identify the depth of ponding required to cause infiltration through the full depth of the tailings column. A 'positive' result is one in which there is no change in matric suction at depth, with changes in matric suction (indicating rewetting of the tailings) 
occurring higher up in the column only. A 'negative' result is indicated by a decrease in matric suction of the lower layers of tailings to near zero, suggesting the tailings are saturated at depth. In the event that infiltration occurs due to ponding, the infiltration flux could be estimated and compared to that for other cover systems.

The parameters required to carry out the model were briefly discussed in Section 4.2. In summary, the parameters required as a minimum include porosity, specific gravity, soil water characteristic curve data, saturated hydraulic conductivity data and site climate data. Further calibration of the model and sensitivity analysis is beyond the scope of this paper, but is ongoing and will be the subject of future papers.

\subsection{Modelling outcomes}

The outcomes of the first model are presented in Figure 13. This model represents a two-year period adopting site climate conditions, including site rainfall, and uses the original soil water characteristic curve data. The model was set up to be saturated on commencement, representing a situation in which deposition has just occurred, saturating the previously-desiccated tailings (see Figure 3 ) and the tailings are then allowed to drain down under site climatic conditions.

In the initial stages (days 0 to 10 ), the pore water pressure (represented by negative matric suction in Figure 13) increases due to drain down of the upper layers of tailings through the base. Beyond day 10, however, the model results show an increasing trend for both the middle and base layers and a slight variation in matric suction at the surface. The measured site rainfall, which was also applied as part of the climate data set, is also shown on Figure 13. The slight variations in surface matric suction generally correspond to the rainfall events, although the rainfall appears to have minimal impact and no evidence of infiltration through the tailings is evident.

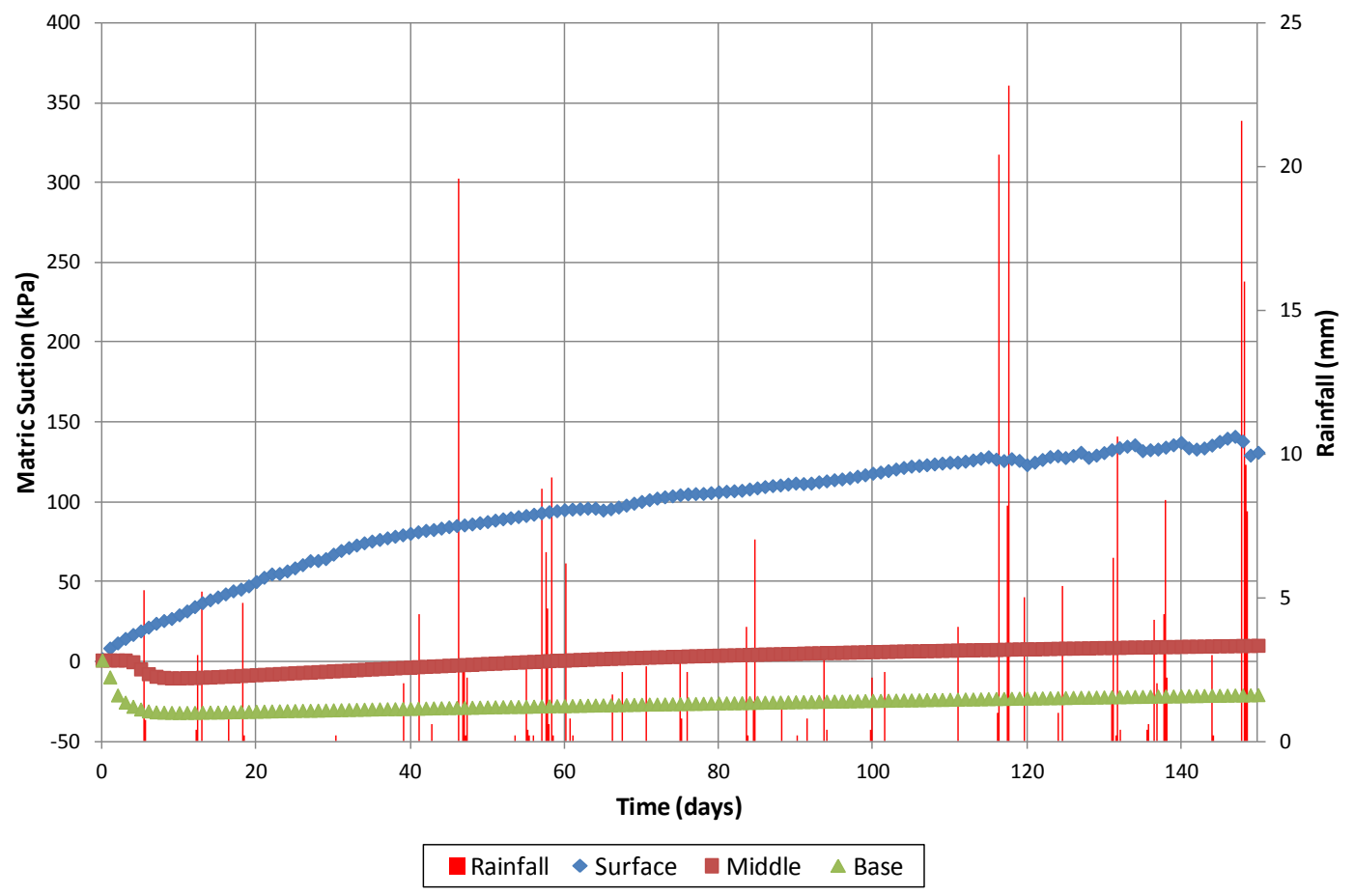

Figure 13 Model results using site climate data and original soil water characteristic curve data

Following the initial model developed to confirm that the site climate data provide reasonable results (Figure 13), a number of model runs were carried out to identify the storm depth required to establish a hydraulic connection through the full depth of the tailings. The modelling runs assumed that a single large rainfall event occurred on day 100 . Ponding events of $100 \mathrm{~mm}, 198 \mathrm{~mm}, 500 \mathrm{~mm}$ and 1,396 mm were selected to capture a range of events, with $198 \mathrm{~mm}$ corresponding to a 1 in 100 year, 72-hour event, and $1,396 \mathrm{~mm}$ corresponding to the theoretical maximum probable precipitation at the site. 
Figures 14 to 16 show the results of the preliminary modelling carried out. In all cases, the surface layer is represented by the upper line, the middle is represented by the middle line and the base layer is represented by the lower line.

Figure 14 shows the results of modelling the ponding from a $100 \mathrm{~mm}$ rainfall event (with no accumulated runoff). It is evident from the results that a $100 \mathrm{~mm}$ rainfall event resulted in wetting up of the surface layer, however, full saturation did not occur (the matric suction values remain above zero). Moreover, there was no impact of the tailings at depth for this storm event.

For the $198 \mathrm{~mm}$ ( 1 in 100 year, 72-hour) and $500 \mathrm{~mm}$ rainfall events, the model suggests that the surface layers will saturate but there is still no evidence of infiltration through to the middle or lower layers. Figure 15 shows the model results for $100 \mathrm{~mm}, 198 \mathrm{~mm}$ and $500 \mathrm{~mm}$ rainfall events. There is a slight decrease in matric suction in the middle layer after the $500 \mathrm{~mm}$ event $(\sim 0.2 \mathrm{kPa})$. However, this is indistinguishable in Figure 15.

Figure 16 shows the results of modelling the $1,396 \mathrm{~mm}$ rainfall event (the probable maximum precipitation) in comparison to the $100 \mathrm{~mm}$ event results (Figure 14). Clearly, the model indicates that the a ponding depth equivalent to probable maximum precipitation rainfall depth results in saturation of the tailings at depth, with positive pore water pressures developing through all layers of the tailings. The rate of infiltration and the pore pressure changes are useful outputs of the model, however, this is beyond the scope of this paper. It is noted that this event is likely to cause flooding across the entire site and have far reaching impacts beyond the TSF. Nevertheless, it is clear that if the closure criteria include consideration ponding equivalent to the probable maximum precipitation depth, the closure design may need to allow for spilling to reduce the likelihood of ponding depths exceeding $500 \mathrm{~mm}$, the depth at which limited infiltration occurred.

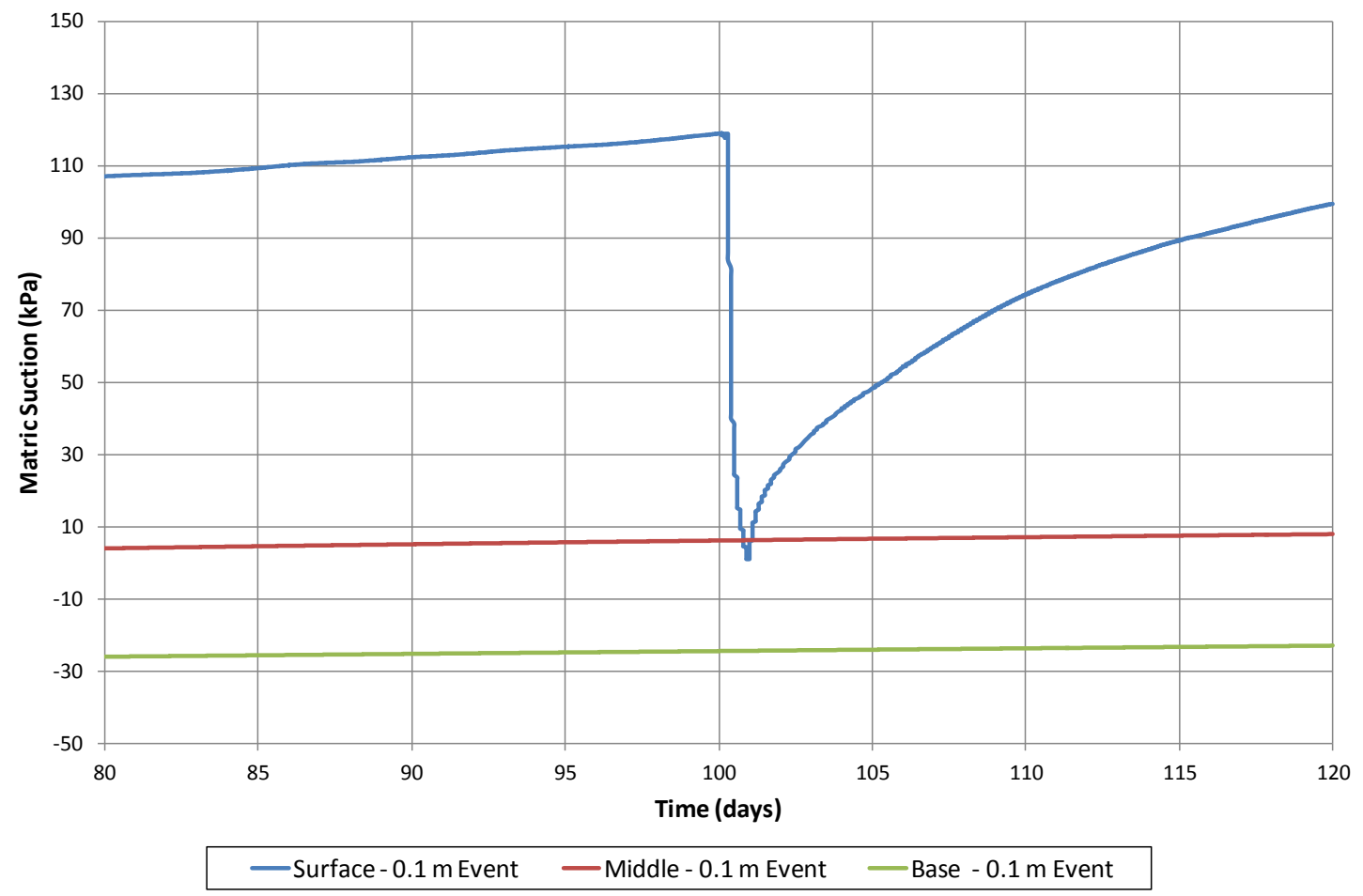

Figure 14 Results of modelling a $100 \mathrm{~mm}$ rainfall event at day 100 


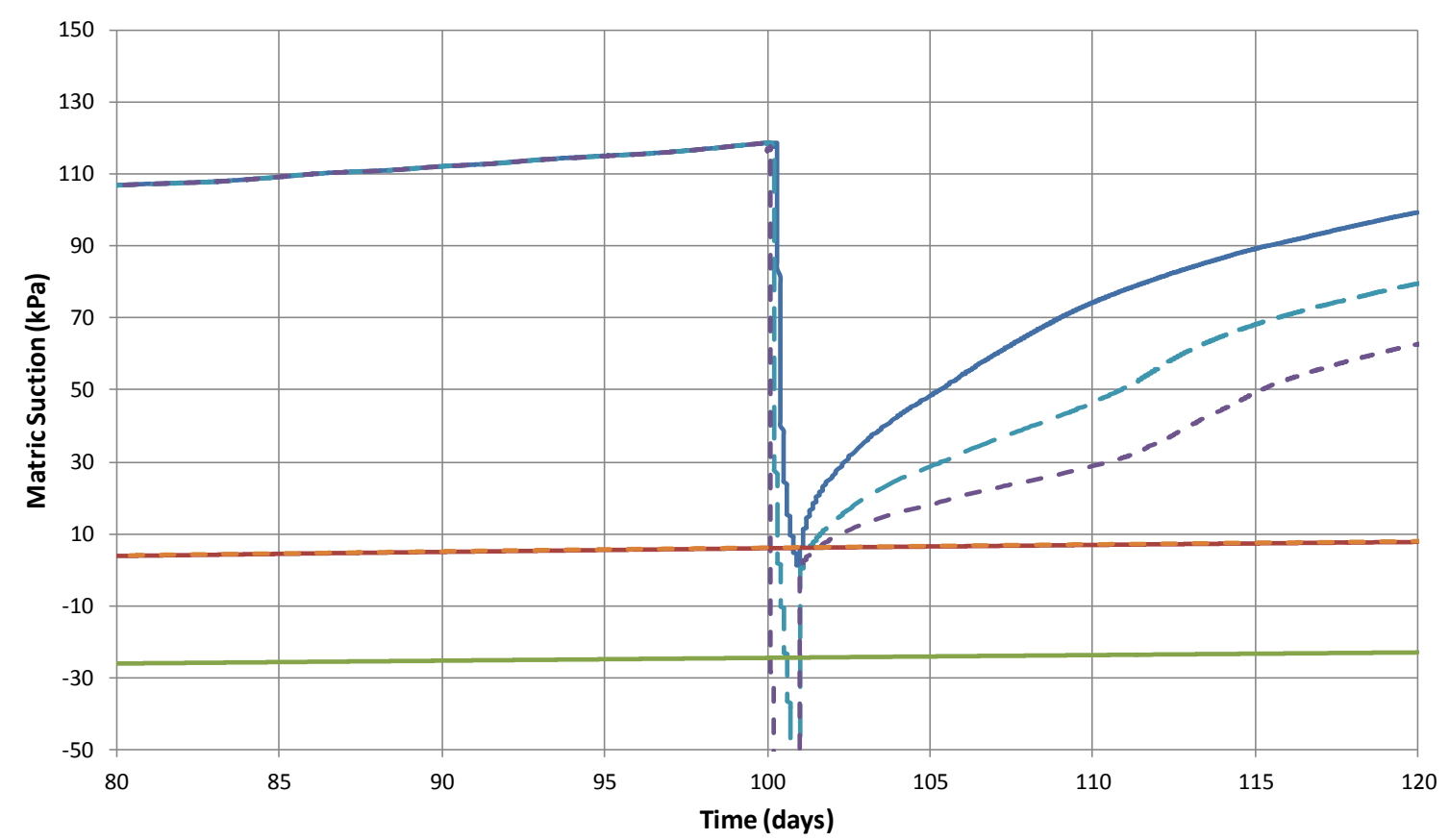

\begin{tabular}{|cc|}
\hline Surface-0.1 m Event & - Surface-0.198 m Event - - Surface-0.5 m Event \\
- Middle-0.1 m Event & - Base - $0.1 \mathrm{~m}$ Event $\quad--$ Middle $-0.5 \mathrm{~m}$ Event \\
\hline
\end{tabular}

Figure 15 Results of modelling surface response to various rainfall events at day 100

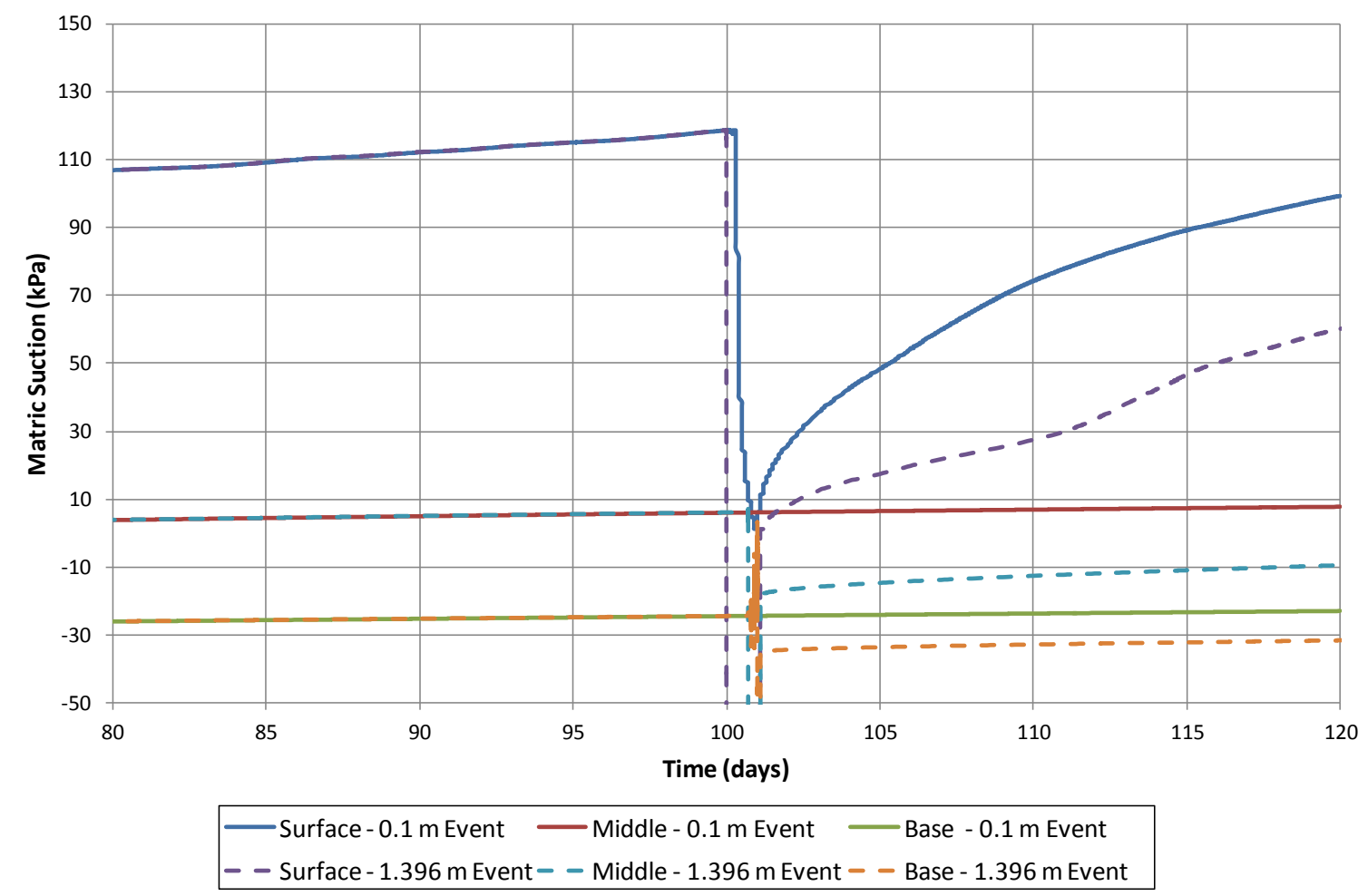

Figure 16 Results of modelling a 1,396 mm rainfall event at day 100

\section{Conclusions}

A research project is being carried out to identify whether or not tailings in an arid climate will desiccate to the extent that ponding from incident rainfall, even in excess, will infiltrate through the full depth of the tailings and hence re-form a hydraulic connection with the groundwater, causing seepage to the 
environment. If this is shown not to occur, the tailings could form part of a store and release cover, with the low hydraulic conductivity of the desiccated tailings effectively providing a 'sealing' layer.

Numerical modelling has been carried out to identify the ponding depth required to cause infiltration through the full depth of the desiccated tailings column. Using field and laboratory data, including the material porosity and specific gravity, soil water characteristic curve data, site climate data, and the measured saturated hydraulic conductivity for the tailings, a preliminary model was developed to predict the extent of infiltration from various rainfall events.

The preliminary modelling indicates that the tailings are likely to mimic a store and release cover system for ponding depths up to about $500 \mathrm{~mm}$ (modelled to result from rainfall in one day and representing about twice the average annual rainfall for the site; hence very much a worst case). Rainfall events beyond this may need to be considered in the design of closure measures, if the agreed closure criteria include consideration of the probable maximum precipitation.

Further calibration of the models and sensitivity modelling is beyond the scope of this paper, but is ongoing and will be the subject of future papers.

\section{Acknowledgement}

The authors of this paper would like to acknowledge Golder Associates (Perth Office), UQ, Xstrata and Cosmos site personnel for ongoing support of the project.

\section{References}

Allen, R.G., Pereira, L.S., Raes, D. and Smith, M. (1998) FAO Irrigation and Drainage Paper No. 56 - Crop Evapotranspiration. ANCOLD (2011) Australian National Committee on Large Dams. Guidelines on Tailings Dams, Planning, Design, Construction, Operation and Closure, Australian National Committee on Large Dams, May 2012.

BoM (2012) Bureau of Meteorology. Internet web page http://www.bom.gov.au/, accessed 12 May 2012.

Campbell Scientific Inc. (2009) 229 Heat Dissipation Matric Water Potential Sensor, Revision 5/09.

Campbell Scientific Inc. (2010) CS215 Temperature and Relative Humidity Probe, Revision 10/10.

Chapman, P.J., Williams, D.J., Rohde, T. and Ennor, S.J. (2008) Understanding the Water Balance of Potentially Acid Forming Tailings Deposited in a Dry Climate, in Proceedings Third International Seminar on Mine Closure (Mine Closure 2008), A.B. Fourie and M. Tibbett, I.M. Weiersbye, P. Dye (eds), 14-17 October 2008, Johannesburg, South Africa, Australian Centre for Geomechanics, Perth, pp. 400-409.

Chapman, P.J., Williams, D.J. and Rohde, T. (2009) Unsaturated Behaviour of Tailings during Deposition and Desiccation Cycles with Reference to Closure Design, in Proceedings of Fourth Asia Pacific Conference on Unsaturated Soils (UNSAT2009), Newcastle, Australia, 23-25 November 2009, pp. 477-482, CRC Press/Balkema, The Netherlands.

Fredlund, M.D., Fredlund, D.G. and Wilson, G.W. (1997) Prediction of the soil water characteristic curve from grain size distribution and volume mass properties, in Proceedings of Third Brazilian Symposium on Unsaturated Soils, Rio de Janeiro, Brazil, 22-25 April 1997, $12 \mathrm{p}$.

Fredlund, D.G., Xing, A. and Huang, S. (1994) Equations for the soil-water characteristic curve, Canadian Geotechnical Journal, Vol. 31, No. 3, pp. 521-532.

INAP (2009) The International Network for Acid Prevention. Global Acid Rock Drainage Guide (GARD Guide), http://www.gardguide.com/.

Qian, X., Koerner, R.M. and Gray, D.H. (2002) Geotechnical Aspects of Landfill Design and Construction, New Jersey: Prentice Hall, Upper Saddle River.

UNEP (1992) United Nations Environment Programme. World Atlas of Desertification. 